Engineering and Computational Mechanics Volume 165 Issue EM4

Briefing: Role of connections in preventing steel frame collapse in fire

Burgess and Davison
Proceedings of the Institution of Civil Engineers

Engineering and Computational Mechanics 165 December 2012 Issue EM4 Pages 219-221 http://dx.doi.org/10.1680/eacm.12.00013

Paper 1200013

Received 10/09/2012

Published online 06/11/2012

Keywords: fire engineering/steel structures/thermal effects

ICE Publishing: All rights reserved

\title{
Briefing: Role of connections in preventing steel frame collapse in fire
}

Ian W. Burgess BA, PhD, CEng, MiStructE

Professor, Department of Civil and Structural Engineering, University of Sheffield, Sheffield, UK
J. Buick Davison BEng, PhD, CEng, MICE

Senior Lecturer, Department of Civil and Structural Engineering, University of Sheffield, Sheffield, UK

The resistance of steel-framed buildings to progressive collapse in fire is reliant on robust performance of the connections between beams and columns. Ian Burgess and Buick Davison of the University of Sheffield explain how the behaviour of connections in fire can be understood using component-based models.

The dramatic film coverage of the twin towers of the World Trade Center has provided an enduring image of progressive collapse, caused by the effects of fire on buildings that had withstood the considerable physical damage caused by aircraft impact. The total collapse, later on the same day, of a nearby 47 -storey building ('7 World Trade'), which had seemed to have taken relatively minor damage, is less well remembered but would, in a more normal context, have been viewed as a cause for particular concern. A series of reports (Arup, 2003; FEMA/ASCE, 2002; IStructE, 2002; NIST, 2003) has focused attention on the need to design and construct robust structures capable of coping with different types of accidental or malicious damage.

When considering the resistance to progressive collapse in fire of modern buildings using steel framing or composite steel-concrete floor systems, the most vulnerable parts of such structures are the connections between beams and columns. These are usually designed to carry forces under ambient-temperature loadings that are easily defined and calculated. However, in fire conditions, the response of the connected beams causes a complex variation of forces of types and magnitudes for which the connections have almost certainly not been designed. Consider the typical variation of 'tying' forces (force components perpendicular to the column face) applied by beams to the connections as temperatures rise and fall during the progress of a building fire. An example is presented in Figure 1, which shows the normal force component transferred through the connections from the beam to the column as the beam temperature increases. The material properties that influence this variation most directly are thermal expansion and strength degradation with temperature. Heating of a steel downstand beam causes a free thermal expansion that, if stiffly restrained (Figure 1(a)) by surrounding structure such as protected columns, cooler beams, attached concrete slabs or braced bays, generates very high axial compressive stresses. The net compression, hogging bending and shear force near to the beam ends tend to cause a combination of localised shear buckling of the beam web and lower-flange buckling, which becomes more likely as steel temperatures rise. If the beam's free thermal expansion can be accommodated by soft, ductile surrounding

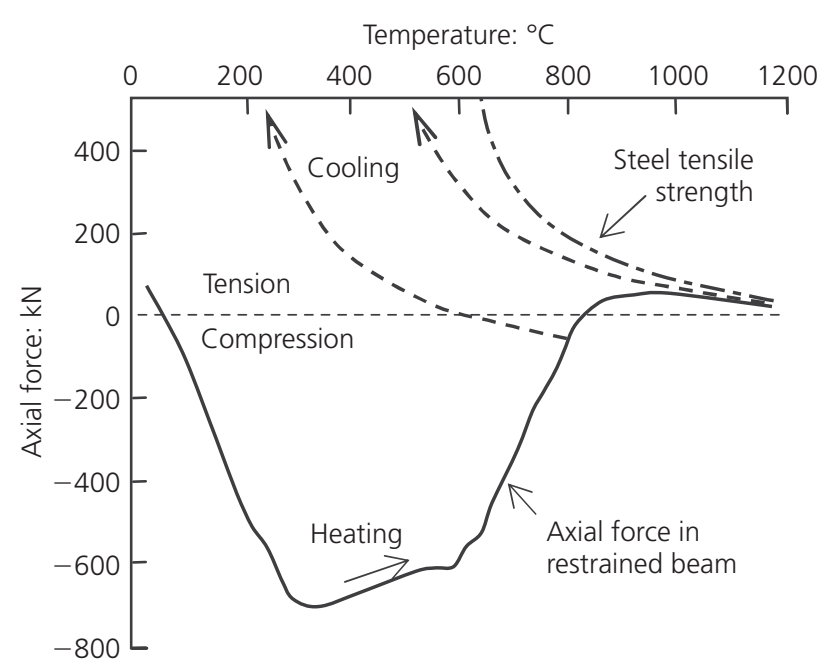

(a)

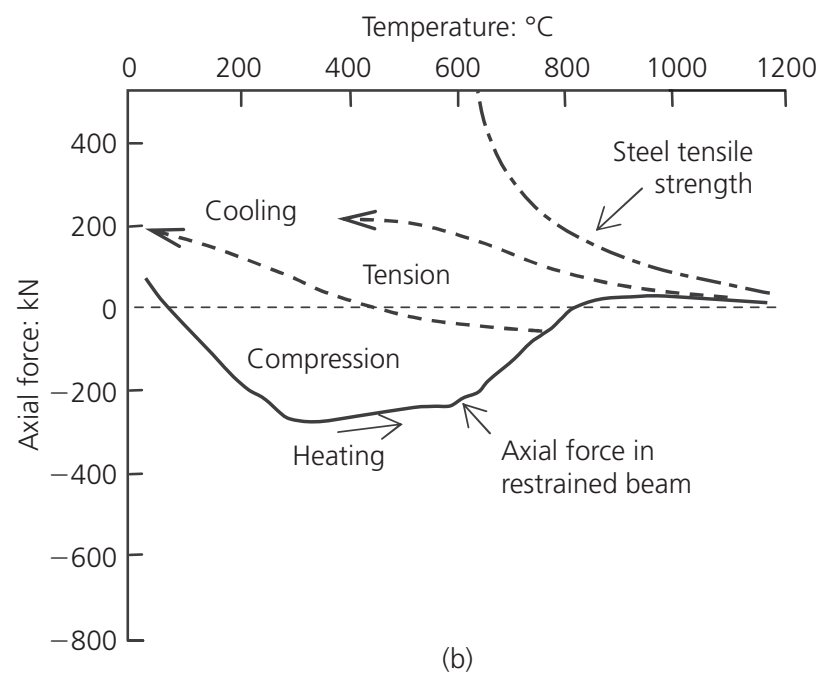

Figure 1. Tying force in typical beam-column connections as the beam temperature increases: (a) stiff restraint to horizontal movement; (b) ductile restraint to horizontal movement 
structure, then the initial build-up of compression force will be greatly lessened (Figure 1(b)). As temperatures rise further, the net compression is progressively reduced by sagging deflection of the beam and by loss of material strength and stiffness. At very high temperatures, nearly all the beam's bending stiffness has been lost, and it hangs, essentially in catenary tension, between its end connections, eventually deflecting just enough to balance its net tensile capacity against the catenary tension caused by its loading and deflection. If the beam is cooled from any peak temperature, the recovery of its thermal expansion as the material stiffens will generate high-tensile (tying) forces between its ends. If the connections, or surrounding structure, are ductile during the tension phase, then the catenary tension will be reduced, as will the enhanced tension caused by cooling.

Connections at the ends of heated steel beams are the first link in the load path of these restraint forces, and are also potentially the most vulnerable components in the chain, very rarely being designed specifically for ductility in tying action. In UK practice, connections are usually designed as 'simple', with the principal role of resisting the vertical reactions at beam ends, but with a nominal tying (normal tension) strength requirement.

Over recent years, high-temperature component models of the main zones of structural action of the connections have been developed (Burgess et al., 2012). These simplified models allow connections to be represented fairly simply in global thermostructural modelling of whole structures or large sub-structures, including the effects of restraint and connection tying ductility described above. A key aspect of the formulation of component models has been found to be their behaviour when force reversal occurs at any given temperature. The reasons for this are twofold: first it is clear from Figure 1 that tying forces can reverse very considerably, both during heating and when cooling occurs; second, when the temperature at any location in the structure changes, the material's stress-strain curve changes, and it is necessary to relate the new curve to the previous one in terms of the permanent displacement that has been acquired. Hence, even if physical force reversal ('unloading') is not a major factor, a force-reversal rule needs to be established unless the material is simply non-linear elastic. The Sheffield component models for high temperatures have used variants of the Masing rule as their assumption for reversal, but no high-temperature experimental work has yet been done to verify the behaviour of connection components when the force is reversed.

Tests carried out at Sheffield and Manchester (2005-2008) demonstrated that, within the 'catenary tension' phase of behaviour, connections from the normal range used in simple or semirigid construction have distinctly different degrees of ductility (Wang et al., 2010). In terms of rotation, the least ductile were fin plates, which were found to fail suddenly at low rotation angles. The most ductile were web cleats, which gain considerable ductility, both in tying displacement and rotation by plastically unfolding their cleat angles. The effect of thermal strain of long-span beams being resisted by bolts in shear was amply illustrated by the connection failure, and consequent progressive collapse, of Building 7 of the World Trade Center (NIST, 2008). An ideal connection to cope with the beam-end movements, both inwards in the initial expansion phase and then outwards in the catenary phase, would allow these movements without being damaged and without generating high normal forces.

Progressive failure of a connection is usually characterised by sequential fracturing at the bolt rows. The nature of these fractures depends on the layout and detailing of the connection; typical failure at the level of a bolt row may be by bolt breakage (tensile or shear failure, possibly accompanied by bolt bending) or by plate failure (tension, block shear, tearing or punching shear). In a component-based joint model, bolt rows generally correspond to a group of components, representing the behaviour of the bolts and plates at that level, connected in series so that the weakest component is the first to break. Because of the large rotations that occur in fire, it is quite common for the highest component row of a beam-column joint to fracture first. Stability of equilibrium is lost at this point, but extra deformation may mobilise sufficient strength in the remaining rows to avoid a total failure of the connection. The structural behaviour when components begin to fail may involve a sequence of such short-term losses of stability that re-stabilise, as is often observed in furnace tests to destruction. Most numerical solution processes, even in the highly developed finite-element packages used for advanced structural analysis by the leaders in structural fire engineering design, will fail to converge at the initial loss of stability. The Vulcan software (www.vulcan-solutions.com), which has been developed at Sheffield for structural fire modelling, has recently been developed to a static/dynamic formulation that changes from static analysis at a loss of stability to an explicit dynamic analysis (Sun et al., 2012) so that the dynamic movements experienced in a laboratory test are traced numerically. When a new stable equilibrium state is encountered, the analysis changes back to static. Thus, there are no unexplained 'failures' to be taken on trust by the user; collapse is simply dynamic movement that does not re-stabilise. The behaviour shown in Figure 2, for a simple frame with a column, a beam and its connections heated in a single compartment, illustrates how effectively this process works. Five-bolt endplate connections at the ends of the heated beam fracture row by row from the top to the bottom; each of these fractures would usually halt a static analysis, but the sequence is followed until the ends of the beam are both detached from the column and it falls under gravity. The heating of the column $\mathrm{C} 1$ continues, however, and its buckling when the steel temperature is in the region of $700^{\circ} \mathrm{C}$ causes the final collapse of the frame.

The coming-together of this type of solution process, the component-based connection element and temperature-dependent analytical models, which represent behaviour up to fracture of the components of a few common connections, should allow full- 


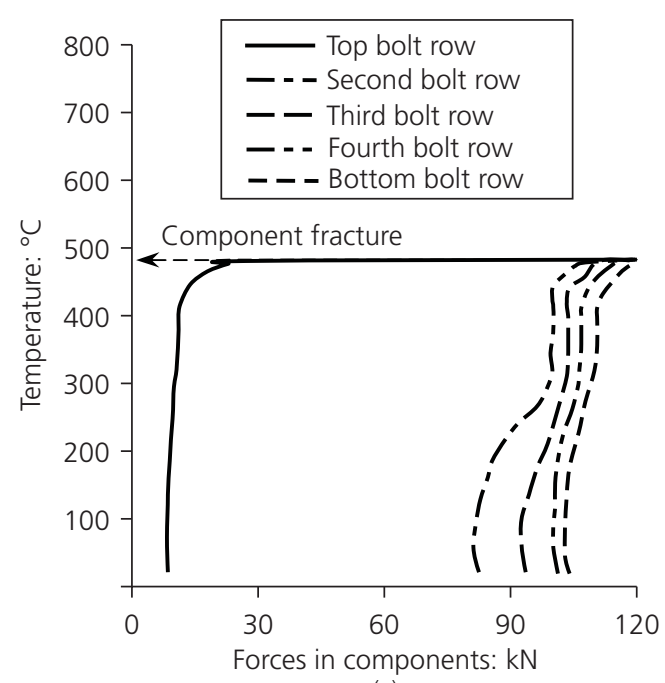

(c)

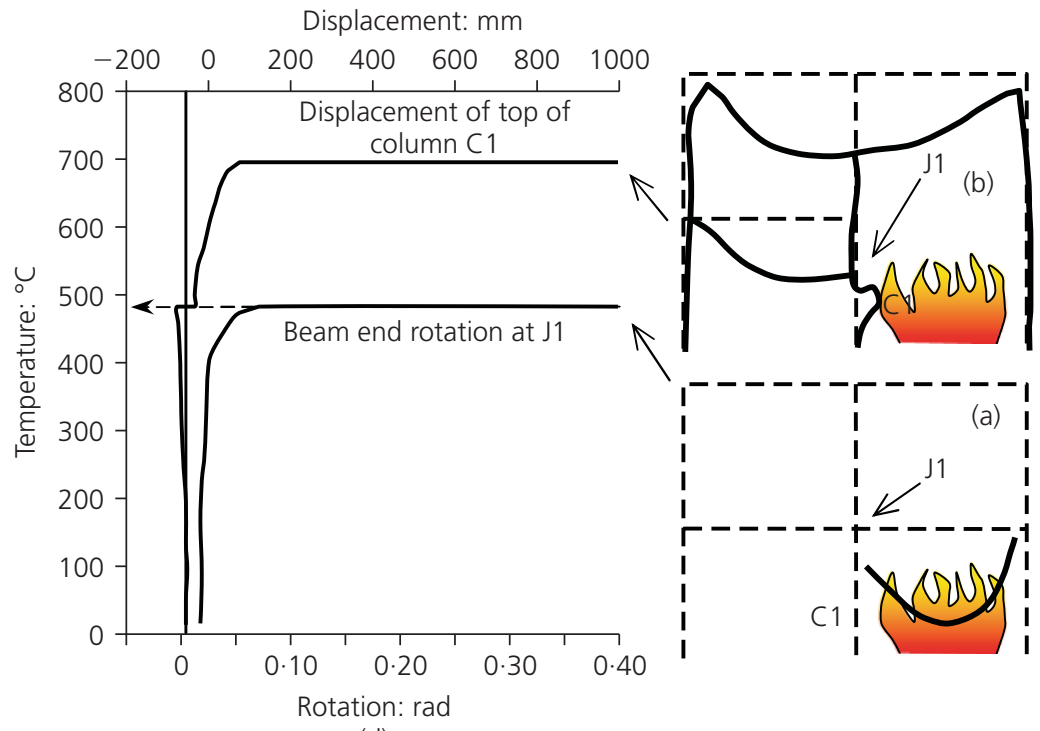

(d)

Figure 2. Progressive collapse of a simple frame with five-boltrow endplate connections, in fire. (a) Fall of beam over fire compartment, following progressive bolt row fracture, shown in (c) for joint J1; (b) buckling of column C1; (d) displacements corresponding to both stages of failure

structure robustness modelling to become the core analytical process for performance-based structural fire engineering design. Before this can become routine, models of component behaviour must be proposed and verified for their complete range of behaviour from tension to compression, including deformation reversal.

\section{REFERENCES}

Arup (2003) A Scoping Study - the Building Regulations: Post September 11. Report to Office of Deputy Prime Minister. Arup, London, UK.

Burgess IW, Davison JB, Huang S-S and Dong G (2012) The role of connections in the response of steel frames to fire. Structural Engineering International (in press).

FEMA (Federal Emergency Management Agency)/ASCE (American Society of Civil Engineers) (2002) World Trade Center Building Performance Study. FEMA/ASCE, Washington, DC and New York, NY, USA.

IStructE (Institution of Structural Engineers) (2002) Safety in Tall Buildings and Other Buildings with Large Occupancy. IStructE, London, UK.

NIST (National Institute of Standards and Technology) (2003) Prevention of Progressive Collapse: Report on July 2002 National Workshop and Recommendations for Future Efforts. Multi Hazard Mitigation Council of National Institute of Standards and Technology, Washington, USA.

NIST (2008) Final Report on the Collapse of World Trade Center Building 7. NIST, Washington, USA.

Sun RR, Huang Z and Burgess IW (2012) Progressive collapse analysis of steel structures under fire conditions. Engineering Structures 34: 400-413.

Wang YC et al. (2010) The safety of common steel beam/column connections in fire. The Structural Engineer 88(21): 26-35.

\section{WHAT DO YOU THINK?}

To discuss this paper, please email up to 500 words to the editor at journals@ice.org.uk. Your contribution will be forwarded to the author(s) for a reply and, if considered appropriate by the editorial panel, will be published as a discussion in a future issue of the journal.

Proceedings journals rely entirely on contributions sent in by civil engineering professionals, academics and students. Papers should be 2000-5000 words long (briefing papers should be 1000-2000 words long), with adequate illustrations and references. You can submit your paper online via www.icevirtuallibrary.com/content/journals, where you will also find detailed author guidelines. 